\title{
NOVAS PERSPECTIVAS DOS ESTUDOS DE SATISFAÇÃO DE USUÁRIOS
}

\author{
Luciana Ferreira da Costa \\ Mestre em Ciência da Informação pela UFPB \\ Professora do Departamento de Ciência da Informação \\ Universidade Federal da Paraíba \\ $\underline{\text { lucianna.costa@yahoo.com.br }}$
}

Francisca Arruda Ramalho

Doutora em Ciências da Informação pela

Universidad Complutense de Madrid, Espanha Professora do Departamento de Ciência da Informação Universidade Federal da Paraíba arfrancisca@hotmail.com

\section{Resumo}

Este paper é fruto das discussões e práticas de pesquisa acerca da satisfação de usuários da informação, originadas do Grupo de Pesquisa Leitura, Organização, Representação, Produção e Uso da Informação vinculado ao Programa de Pós-Graduação em Ciência da Informação da Universidade Federal da Paraíba, tendo como laboratório a disciplina Usuários da Informação deste programa. Discute a definição de satisfação relacionada às necessidades humanas, privilegiando a ótica informacional diante da sua importância na atualidade, a Era da Informação. Apresenta a evolução dos estudos de satisfação relacionados ao uso da informação através dos modernos sistemas interativos nas perspectivas dos Estudos de usuários da Ciência da Informação e dos Estudos de usabilidade da Ciência da Computação, propondo os Estudos Híbridos de Uso da Informação.

Palavras-chave: Satisfação. Uso da informação. Usuários da informação. Estudos de Usuários. Usabilidade. 


\section{NINGUÉM PERMANECE SATISFEITO}

I can't get no... Satisfaction!

I can't get no... Satisfaction!

'Cause I try, and I try, and I try, and I try!

I can't get no... Satisfaction!

The Rolling Stones

A revolução informacional, potencializada pelas Tecnologias da Informação e Comunicação (TIC), tem assumido, mundialmente, um significativo papel no desenvolvimento da sociedade contemporânea, demarcando a Era da Informação, conforme denominou Manuel Castells (1999), uma era que se iniciou pela adaptação ao fenômeno da "explosão informacional" no período pós-guerra na segunda metade do século XX (SARACEVIC, 1996).

Assim, desde o fenômeno da "explosão informacional", novas relações sócio-técnicas foram desencadeadas e, diante delas, um consequente sentimento humano foi provocado, ou melhor, potencializado: a "ansiedade da informação" (WURMAN, 1991), caracterizada por fenômenos somáticos comportamentais instaurados em face da informação em contextos como: necessidade, vontade, falta, excesso, presença, uso.

Diante da ansiedade da informação, tornou-se imprescindível o estudo da satisfação dos usuários, considerando a sua implicação na relação entre as crescentes necessidades individuais e institucionais de informação e a oferta de estoques de informação, de modo não diferente, cada vez maiores e mais especializados. Em atenção a essa relação, instituições vêm utilizando sistemas de informação cada vez mais similares competitivamente, eficientes e velozes, em disputa por atração, suprimento, conquista e fidelização de usuários, utilizando, para tanto, a busca e renovação de sua satisfação.

Mais do que nunca, se torna apropriada a velha máxima de Sêneca: "Ninguém permanece satisfeito com o que tem", pois ainda, pelo adágio popular: “conhecer é poder".

Daí o verbete satisfação significar ao mesmo tempo "Contentamento, alegria, deleite, aprazimento", "Pagamento, recompensa, retribuição" e "Explicação, justificativa, justificação" (FERREIRA, 2004), isto porque a satisfação está estritamente relacionada às ações e aos resultados das ações humanas diante do que se deseja ou do que se necessita.

O homem é um ser insaciável por natureza, está constantemente insatisfeito. Como um ciclo, o processo de satisfação individual desencadeia novas necessidades e novos processos individuais de busca pela continuidade de satisfação. 
A questão da satisfação humana aplicada, então, às possíveis e diversas práticas informacionais - de geração, armazenamento, busca, recuperação, acesso, uso, transferência e disseminação da informação, conforme tratam Araújo (1998) e Marteleto (1992) - tem relevância cada vez maior na atualidade diante do uso das TIC.

Apresentamos, portanto, este trabalho como fruto das discussões e práticas de pesquisa acerca da satisfação de usuários da informação originadas do Grupo de Pesquisa Leitura, Organização, Representação, Produção e Uso da Informação vinculado ao Programa de PósGraduação em Ciência da Informação (PPGCI) da Universidade Federal da Paraíba (UFPB), tendo como laboratório maior o espaço de compartilhamento de experiências interdisciplinares e de cooperação acadêmica promovido pela disciplina Usuários da Informação deste programa.

Devemos mencionar, ainda, a contribuição do Grupo de Pesquisa Leitura, Organização, Representação, Produção e Uso da Informação e da disciplina Usuários da Informação do PPGCI no relacionamento com os Cursos de Graduação em Biblioteconomia e em Arquivologia da UFPB, através da interação com a disciplina Estudo de Usuários do Departamento de Ciência da Informação, da atividade de Estágio Docência e da Iniciação Científica.

A partir daí, compreendemos a necessidade de se promover uma regeneratividade dos estudos de satisfação de usuários por parte da Ciência da Informação.

\section{NECESSIDADES $\leftrightarrow$ INFORMAÇÃO $\leftrightarrow$ SATISFAÇÃO}

O que move os homens?

As suas necessidades os movem.

Abraham Harold Maslow, teórico da Psicologia, idealizou uma das mais importantes teorias de motivação, reconhecida pela denominação que leva o seu nome: Teoria de Maslow. Esta teoria foi publicada originalmente no seu livro Motivation and Personality. Nesta obra, Maslow analisa o comportamento motivacional como consequência das necessidades humanas. Para ele, as necessidades dos seres humanos estão sujeitas a uma hierarquia, o que implica dizer que quando o ser humano concretiza uma necessidade surge outra em seu lugar, fazendo com que o homem busque formas de satisfazê-la. Em resumo, a Teoria de Maslow (1954) versa sobre a organização ou o arranjo da motivação e a ação humana em níveis das 
suas necessidades, numa sequência de relevância e de influência que pode ser representada em forma de pirâmide.

Aldo Barreto (2002), pesquisador brasileiro da Ciência da Informação, baseado na pirâmide das necessidades e comportamentos humanos da Teoria de Maslow, adaptou-a para analisar a demanda e a oferta de informação, relacionando, respectivamente, as necessidades humanas aos estoques de informação existentes. Tal relação se daria numa situação inversamente proporcional entre necessidades e estoques de informação para satisfação das necessidades dos indivíduos, conforme visualizamos em sequência:

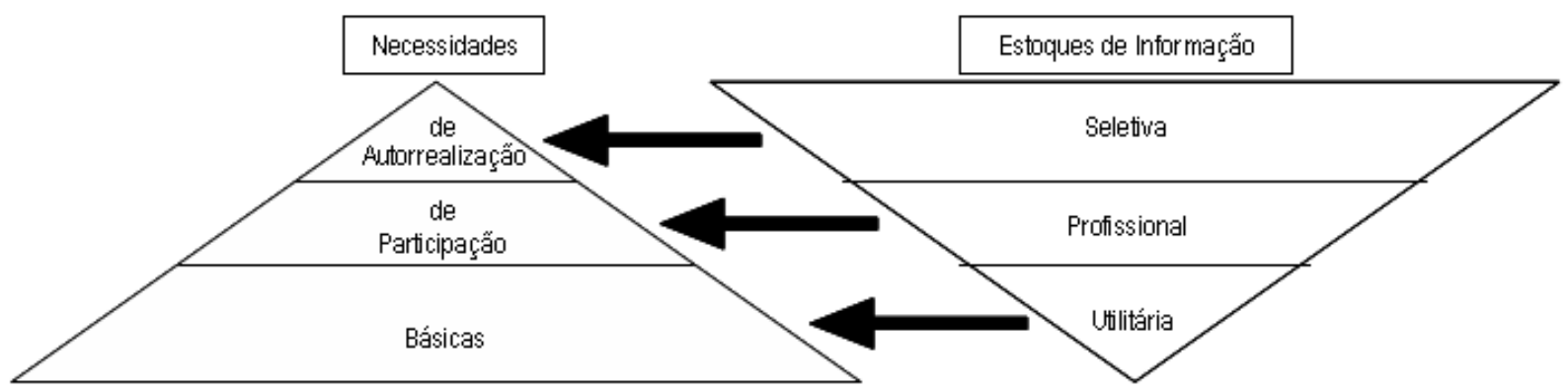

Figura 1: Relação entre necessidades e estoques de informação Fonte: Adaptado de BARRETO, 2002.

Dessa forma, os indivíduos sociais são movidos pelas suas necessidades e buscam informação para sua sobrevivência, continuidade, envolvimento, evolução e autorrealização.

Segundo Figueiredo (1979), enquanto uma perspectiva conceitual importante, dois tipos de necessidades de informação devem ser consideradas: a) a necessidade de informação em função do conhecimento (que resulta do desejo de saber); e b) a necessidade de informação em função da ação (que resulta de necessidades materiais exigidas para a realização das atividades humanas, profissionais e pessoais). Por essa perspectiva, quando tratamos do uso de informação, devemos atentar que produtos/sistemas/unidades de informação emitem/disponibilizam a matéria informação para que esta seja trabalhada, a fim de obter um efeito que satisfaça a uma necessidade de informação a partir de sua função.

O objetivo final de um produto/sistema/unidade de informação deve ser compreendido e analisado, enquanto fontes ou canais de informação utilizados, em termos dos usos da informação e dos efeitos (funções concretizadas) resultantes desses usos na modificação do estado do conhecimento e nas ações dos usuários. Dessa maneira, o papel mais importante do produto/sistema/unidade de informação consiste na forma como a informação 
possibilita/transforma a realização desse objetivo ao satisfazer seus usuários (LE COADIC, 1996).

Em face dessa compreensão, a definição de satisfação, quanto ao uso da informação em atenção às necessidades dos indivíduos, também pode ser explicada a partir do modelo de satisfação de Oliver (1996), denominado de Modelo de Atributos de Produtos/Serviços e representado pictoricamente por elipses circunscritas. Pautando-nos neste modelo, o produto ou serviço de informação seria, enquanto elipse central, composto por atributos que gerariam insatisfação, caso não existissem (considerados "atributos mantenedores", permitindo a continuidade do processo de uso da informação). A próxima elipse, considerada elipse de expectativas, contém as características esperadas para o atendimento às necessidades informacionais. A elipse seguinte é formada por atributos que geram encantamento, que, através da subjetividade do usuário, contribuem para que este último atribua valor/qualidade ao uso efetivado da informação. Finalmente, a última elipse pode ser considerada como concretização da satisfação, conforme podemos observar na Figura 2.

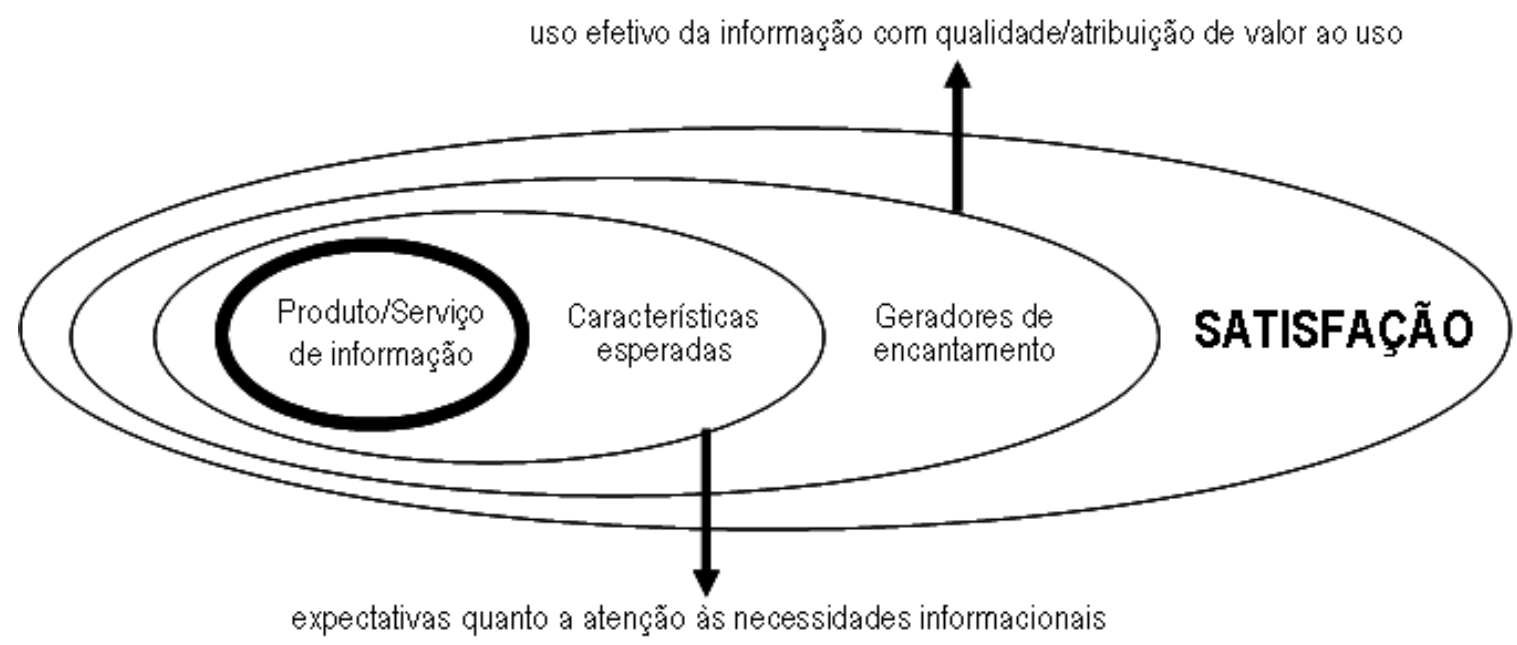

Figura 2: Modelo de Atributos de Produtos/Serviços aplicado à satisfação no uso da informação Fonte: Adaptado de OLIVER, 1996.

Guiados por Anderson e Mittal (1999), advertimos, entretanto, que nem sempre a informação possibilita ou transforma a realização das ações dos usuários, e mais, nem sempre a informação satisfaz seus usuários.

Nesse sentido, este pensamento se aproxima da compreensão da necessidade de existência dos atributos mantenedores, conforme trata Oliver (1996), para que a informação possa possibilitar/transformar a realização das ações dos usuários e, quiçá, em um segundo momento, gerar satisfação. Caso não existam os atributos mantenedores, haverá insatisfação. 
Segundo Beber, Ribeiro e Fogliatto (2004), a insatisfação deve ser reconhecida como uma condição distinta da satisfação quando do uso de produtos e serviços. Para os autores, satisfação e insatisfação não são extremos de um mesmo continuum, pois estão vinculadas à qualidade e atenção às necessidades através de caracterizações e valorações das mais diversas e, por vezes, distintas. A razão da satisfação pode não coincidir com os parâmetros da insatisfação.

Dessa maneira, quanto à insatisfação, para Maslow (1954): quando a qualidade e a atenção às necessidades não se realizam, sobrevém a frustração do indivíduo, que poderá assumir várias atitudes: comportamento ilógico ou sem normalidade, agressividade por não poder dar vazão à insatisfação contida, nervosismo, insônia, distúrbios circulatórios/digestivos, falta de interesse pelas tarefas e objetivos, passividade, baixa autoestima, má vontade, pessimismo, resistência às modificações, insegurança, não colaboração, etc. Com efeito, nesses casos, o ciclo motivacional não se completa como desejado.

Entretanto, quando a necessidade humana não é satisfeita, acontecendo as atitudes descritas, não implica dizer que o indivíduo persistirá sempre frustrado, pois, segundo Maslow, a necessidade será transferida ou compensada de algum modo. Daí, reconhecermos o ciclo motivacional como contínuo.

Em se tratando das necessidades de informação à satisfação dos usuários, portanto, se "necessidades e usos são interdependentes, se influenciam reciprocamente de uma maneira complexa que determinará o comportamento do usuário e suas práticas" (LE COADIC, 1996, p. 39), a satisfação ou insatisfação proveniente dos usos da informação suscitam novas necessidades informacionais, bem como novos comportamentos dos usuários, frente à alteração de seu estado de conhecimento e ação social, como representado na Figura 3.

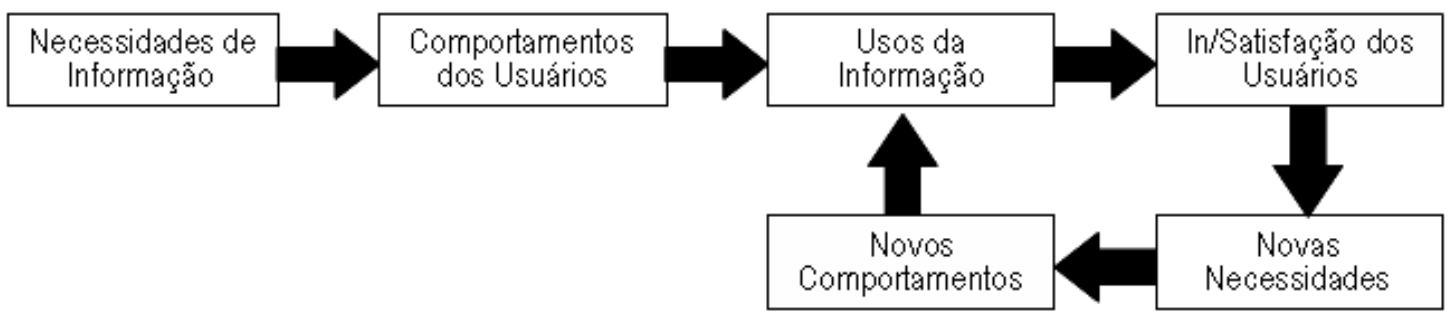

Figura 3: Ciclo das necessidades e usos da informação Fonte: Adaptado de LE COADIC, 1996.

Temos, assim, um ciclo motivacional contínuo de necessidades e usos da informação que persegue a própria existência humana. 


\section{A EVOLUÇÃO DOS ESTUdOS DE SATISFAÇÃO DE USUÁRIOS}

Influenciadas pela Teoria de Maslow, outras teorias surgiram, durante a segunda metade do século $\mathrm{XX}$, propondo estudos de satisfação baseados em métodos científicos de avaliação. Essas propostas se voltaram aos mais diversos campos do conhecimento e aplicações sociais de produtos e serviços oferecidos às pessoas, como a Administração, a Saúde, a Indústria, a Educação, a Cultura, a Comunicação e Informação, etc., compreendendo essas pessoas como referência, enquanto usuários, clientes, pacientes ou consumidores. Para Esperidião e Trad (2006), quatro teorias se destacam originadas, predominantemente, da Psicologia Social e do Marketing, além de uma, que recorre à combinação de modelos, conforme a descrição apresentada no quadro que segue:

\begin{tabular}{|c|c|c|}
\hline TEORIAS & AUTORES & DESCRIÇÃO \\
\hline Teoria da Atitude & Linder-Pelz & $\begin{array}{l}\text { Considera a satisfação uma atitude de avaliação positiva } \\
\text { ou negativa feita pelos indivíduos sobre um determinado } \\
\text { produto/serviço ou um dos aspectos que o compõem. }\end{array}$ \\
\hline $\begin{array}{c}\text { Teoria da } \\
\text { Discrepância }\end{array}$ & $\begin{array}{l}\text { Sitzia e Wood; } \\
\text { Fox e Storms; } \\
\text { Carr-Hill }\end{array}$ & $\begin{array}{l}\text { É considerada a teoria mais utilizada nas pesquisas de } \\
\text { satisfação. A partir das discrepâncias ou diferenças entre } \\
\text { as expectativas e a percepção das experiências dos } \\
\text { indivíduos é que os níveis de satisfação são identificados. }\end{array}$ \\
\hline $\begin{array}{l}\text { Teoria da } \\
\text { Realização ou } \\
\text { Confirmação da } \\
\text { Expectativa }\end{array}$ & $\begin{array}{l}\text { Fitzpatrick e } \\
\text { Hopkins }\end{array}$ & $\begin{array}{l}\text { Propõe-se a compreender a demonstração da satisfação } \\
\text { dos indivíduos quando estes recebem aquilo que } \\
\text { esperavam dos serviços ou mais do que esperavam, } \\
\text { permitindo conhecer o quanto um serviço foi melhor } \\
\text { diante da expectativa inicial. }\end{array}$ \\
\hline $\begin{array}{l}\text { Teoria da } \\
\text { Equidade }\end{array}$ & Souza; Williams & $\begin{array}{l}\text { Introduzindo elementos de comparação social, postula } \\
\text { que os indivíduos avaliam produtos/serviços segundo } \\
\text { critérios de equidade, ou seja, em termos de "ganhos" ou } \\
\text { "perdas" na comparação com outros indivíduos. }\end{array}$ \\
\hline $\begin{array}{c}\text { Teoria dos Quatro } \\
\text { Estágios }\end{array}$ & Swan & $\begin{array}{l}\text { Teoria de "Modelos Combinados", composta por quatro } \\
\text { constructos básicos: } 1 \text { - a percepção do desempenho do } \\
\text { serviço; } 2 \text { - a confirmação da expectativa; } 3 \text { - a satisfação } \\
\text { geral; e } 4 \text { - a intenção de revisitar ou evitar o serviço no } \\
\text { futuro. }\end{array}$ \\
\hline
\end{tabular}

Quadro 1: Teorias produzidas acerca da Satisfação a partir de Maslow Fonte: Adaptado de ESPERIDIÃO; TRAD, 2006. 
Conforme Esperidião e Trad (2006, p. 1268), “Os estudos de satisfação de usuários ganharam destaque na literatura principalmente na década de 1970, nos Estados Unidos e na Inglaterra, inseridos no paradigma do consumismo e da cultura de qualidade". Mesmo assim, as autoras consideram que, segundo a literatura científica, existe "pouco arsenal teórico e metodológico" disponível para esses estudos.

No âmbito da Ciência da Informação, os estudos de satisfação de usuários são considerados uma especificidade dos Estudos de Usuários, área de pesquisa originada da Biblioteconomia e Documentação.

Em sua gênese, os Estudos de Usuários remontam à década de 1940, a partir de dois trabalhos apresentados na Conferência de Informação Científica da Royal Society realizada em 1948: "um acerca do comportamento na busca da informação de duzentos cientistas britânicos [...] e o outro sobre o uso da biblioteca do Museu de Ciência de Londres" (CHOO, 2003, p. 67), sob autoria de John Desmond Bernal (1948) e Donald Urquhart (1948), que vieram contribuir para gerar preocupação com estudos orientados às necessidades dos usuários. Os objetivos e os resultados desses dois trabalhos estão sintetizados no Quadro 2:

\begin{tabular}{|c|c|c|}
\hline Autores & BERNAL & URQUHART \\
\hline Título do Trabalho & $\begin{array}{l}\text { Preliminary analysis of pilot } \\
\text { questionnaire on the use of scientific } \\
\text { literature }\end{array}$ & $\begin{array}{l}\text { The organization of the distribution } \\
\text { of scientific and technical } \\
\text { information }\end{array}$ \\
\hline Objetivos & $\begin{array}{l}\text { - Mapear o desempenho de trabalho } \\
\text { de cientistas leitores de periódicos } \\
\text { científicos, enquanto usuários de } \\
\text { informação científica. }\end{array}$ & $\begin{array}{l}\text { - Conhecer a disseminação e o uso } \\
\text { da informação técnico-científica. }\end{array}$ \\
\hline Resultados & $\begin{array}{l}\text { - Perfil geral dos usuários leitores de } \\
\text { periódicos científicos; e } \\
\text { - Descrição dos hábitos de leitura no } \\
\text { trabalho científico. }\end{array}$ & $\begin{array}{l}\text { - Levantamento das fontes de } \\
\text { informação } \\
\text { utilizadas pela comunidade } \\
\text { científica; e } \\
\text { - Descrição do grau de utilidade das } \\
\text { fontes de informação em relação ao } \\
\text { ano de publicação } \\
\text { - Levantamento dos objetivos dos } \\
\text { usuários ao realizar consultas às } \\
\text { fontes de informação. }\end{array}$ \\
\hline
\end{tabular}

Quadro 2: Síntese dos trabalhos de Bernal e Urquhart Fonte: Adaptado de MARTI-LAHERA, 2004.

A partir daí, os Estudos de Usuários constituíram-se em pesquisas baseadas em métodos científicos objetivos, compreendendo a investigação das necessidades de informação, os 
processos de busca e usos da informação, bem como sua qualificação/satisfação (WILSON, 1981; FERREIRA, 1997; CHOO, 2003). Seguindo essa perspectiva conceitual, Sanz Casado (1994), inspirado na metodologia científica, definiu os Estudos de Usuários como sendo o conjunto de estudos científicos que analisa, qualitativa e quantitativamente, os hábitos de informação dos usuários. Nesse sentido, Guinchat e Menou (1994) consideram os usuários como um fator essencial de todo e qualquer sistema de informação.

Segundo Ferreira (1997), apesar dos Estudos de Usuários remontarem à década de 1940, historicamente, os mesmos privilegiaram os estudos de satisfação de usuários a partir da década de 1970, quando estes surgiram preocupados mais propriamente com o usuário e a satisfação de suas necessidades de informação. Na literatura especializada brasileira sobre a área, os primeiros Estudos de Usuários datam desta década.

Inicialmente, tais estudos se centraram nos diversos sistemas de informação, bibliotecas, arquivos, centros de documentação e seus produtos e serviços, utilizando-se de metodologias eminentemente quantitativas, realizando estudos bibliométricos/cienciométricos, análise de citações, levantamento de visitas/consultas e documentos solicitados/utilizados. Essa primeira perspectiva compreendia a satisfação dos usuários a partir da oferta dos produtos e serviços de informação.

Figueiredo (1979) denominou esses estudos centrados no sistema de estudos sob paradigma clássico e, corroborando Ferreira (1997), os denominou de estudos sob abordagem tradicional. Só a partir da década de 1970, apareceram teorias e metodologias de Estudos de Usuários voltadas à subjetividade e necessidades dos mesmos, incluindo aí a sua satisfação. Centrados nos usuários, esses estudos passaram a adotar metodologias qualitativas e diálogos interdisciplinares com as Ciências do Comportamento e a Administração.

Conforme Figueiredo (1979), esses estudos, por sua vez, foram denominados de estudos sob paradigma moderno ou, conforme Ferreira (1997), estudos sob abordagem alternativa.

Dessa forma, os estudos mais atuais, sob abordagem alternativa, vêm seguindo a tendência das publicações das teorias de satisfação quando tratam desse objeto no âmbito informacional, priorizando novas perspectivas: sócio-culturais, comportamentais, holísticas e cognitivas. Satisfazer o usuário, nessa perspectiva da área, corresponderia a servi-lo, a partir de agora, das demandas do mesmo quanto às suas subjetividades e necessidades de informação.

Pela evolução dos Estudos de Usuários, houve uma reconfiguração dos seus fenômenos informacionais investigados (objetos, contextos, usuários, sistemas, atitudes, necessidades, etc.), a partir do limiar do século XX, em decorrência dos novos produtos e serviços informacionais suscitados diante da popularização/democratização do uso das TIC, Enc. Bibli: Arquivol. Bibliotecon. Ci. Inf., ISSN 1518-2924, Florianópolis, v. 15, n. 30, p.57-73, 2010. 
principalmente a Internet. Em consequência disso, conforme as palavras de Costa (2008, p. 52), nesta primeira década do século XXI:

Os estudos [de usuários] estão voltados tanto para o comportamento informacional quanto para a avaliação de satisfação e desempenho, enfatizando a relação entre usuários e sistemas de informação interativos no contexto social das TIC.

Convergentes aos Estudos de Usuários, nesse último contexto social tecnológico, os Estudos de Usabilidade surgem justamente no final do século XX, no âmbito da Ciência da Computação/Engenharia de Software, também preocupados com a satisfação e o desempenho dos usuários agora nos cenários de uso de produtos e sistemas interativos baseados em computador, ou seja, pautados nas TIC. Tais cenários são amplamente reconhecidos como o campo da Interação Homem-Computador (IHC), o campo da busca pela harmonia na ação exercida mutuamente entre dois fenômenos: um humano e outro artificial (BARANAUSKAS; ROCHA, 2000).

Seguindo a compreensão de IHC, surge o conceito de usabilidade que está diretamente ligado aos conceitos de qualidade de uso de produtos e sistemas tecnológicos utilizados nas mais diversas atividades humanas. Pela definição internacional, a usabilidade é compreendida como "a capacidade de um produto ser usado por usuários específicos para atingir objetivos específicos com eficácia, eficiência e satisfação em um contexto específico de uso" (ISO 9241-11, 1998).

Precursor dos Estudos de Usabilidade, Nielsen (1993) indica que a satisfação, tratada por ele como Satisfação Subjetiva, refere-se ao usuário achar agradável a interação com um sistema e se sentir particularmente satisfeito. A Satisfação Subjetiva seria um atributo de usabilidade complementar a mais quatro outros atributos, que devem ser observados para a análise da qualidade de uso de um produto ou sistema interativo: facilidade de aprendizado, eficiência de uso, facilidade de memorização e baixa taxa de erros.

Mesmo que o usuário tenha facilidade em aprender a utilizar um sistema de informação ou qualquer outro produto tecnológico informacional, consiga o memorizar facilmente, utilize-o com eficiência enfrentando a menor quantidade de obstáculos possíveis, diminuindo seus erros nessa atividade, sem satisfação, nada importaria.

A subjetividade do usuário, em relação à sua satisfação, conta tanto ou mais quanto o seu desempenho no permanente retorno ao sistema. Quanto mais satisfeito o usuário se sentir, 
maior a usabilidade do sistema (NIELSEN, 1993, 1997, 2000; NIELSEN; LORANGER, 2007).

Publicada em 1998 pela International Organization for Standardization (ISO), a ISO 9241, enquanto norma de padrão internacional do estabelecimento de requisitos ergonômicos para o trabalho de organizações com terminais computacionais de visualização, define satisfação assim vinculada à usabilidade:

Satisfação - conforto e aceitabilidade do produto, medidos por meio de métodos subjetivos e/ou objetivos. As medidas objetivas de satisfação podem se basear na observação do comportamento do usuário (postura e movimento corporal) ou no monitoramento de suas respostas fisiológicas. As medidas subjetivas, por sua vez, são produzidas pela quantificação das reações, atitudes e opiniões expressas subjetivamente pelos usuários (ISO 9241 - Parte 11, 1998).

Habitualmente, para medir a satisfação de usuários, mais do que levantamentos de perfis de usuários, os Estudos de Usabilidade se utilizam da aplicação de questionários de satisfação, sejam enfatizadas medidas objetivas ou subjetivas. Sendo o Questionaire for User Interface Satisfaction-QUIS, desenvolvido por Ben Shneiderman e sua equipe da University of Maryland (SHNEIDERMAN, 1987; SHNEIDERMAN; PLAISANT, 2004), o mais conhecido e utilizado como modelo/parâmetro internacional.

Assinalamos, com base em Cybis (2007, p. 124-125), as alternativas de questionários de satisfação mais conhecidas e suas respectivas fontes de acesso:

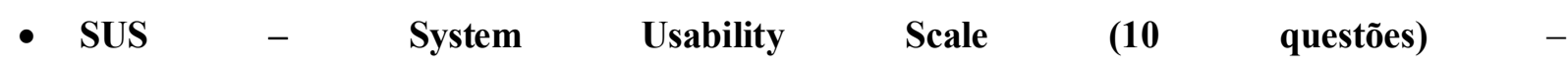
http://www.usability.serco.com/trump/documents/Suschapt.doc;

- SUMI - Software Usability Measurement Inventory (5 fatores; 50 questões) http://www.ucc.ie/hfrg/questionnaires/sumi/index.html;

- QUIS - Questionnaire for User Interaction Satisfaction (versão 5; 4 fatores; 21 questões) http://www.www.lap.umd.edu/QUIS/indez.html;

- ISONORM 9241:10 - Questionário baseado na parte 10 da norma ISO 9241 (7 fatores; 34

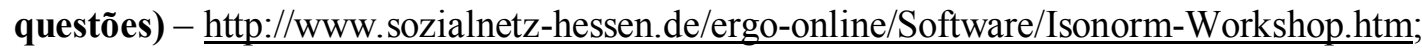

- WAMMI - Website Analysis and Measurement Inventory - http://www.wammi.com/whatis.html;

- $\quad \mathbf{U S E}$ - http://www.mindspring.com/ alund/USE/IntroductionToUse.html;

- CSUQ - http://www.acm.org/ perlman/question.cgi?form=CSUQ; e

- IsoMetrics - http://people.freenet.de/gediga/bit99.htm. 
$\mathrm{Na}$ atualidade, os Estudos de usabilidade se tornaram uma exigência. Uma boa usabilidade implica na promoção de novas relações sócio-técnicas e na sobrevivência de pessoas e instituições, através da aceitação de (satisfação quanto aos) serviços e produtos. Já a má usabilidade, pode implicar, por sua vez, na construção de imagens ruins de pessoas e instituições, em sua desarticulação/ineficiência ou até falência. Dessa forma, o consumismo relacionado à competitividade dos mercados globalizados contribui para a necessidade desses estudos.

Daí, por questões de alto financiamento/investimento econômico acerca dos produtos tecnológicos, os Estudos de usabilidade tendem às aplicações mais comerciais, diferentemente dos Estudos de usuários, mais institucionais e sociais. Nesse sentido, conforme Cybis (2007), os Estudos de usabilidade têm se voltado ao comércio eletrônico, governo eletrônico, jogos de computador, software de gestão, TV digital e, mais recentemente, à interação móvel, enquanto que os Estudos de usuários, conforme Sanz Casado (1994), tradicionalmente, voltam-se às instituições promotoras de serviços de informação ou unidades de informação, como bibliotecas, arquivos, museus e centros de documentação.

Entretanto, a promoção dos estudos de satisfação sob perspectiva dos Estudos de usabilidade provoca a regeneratividade dos estudos de satisfação sob perspectiva dos Estudos de usuários. Regeneratividade enquanto ação de se regenerar, de dar vida nova (FERREIRA, 2004). Nessa perspectiva, devemos ressaltar que, relacionando os Estudos de usuários aos Estudos de Usabilidade, autores da Ciência da Informação já vêm contribuindo com esse diálogo, realizando pesquisas e publicando a respeito desse nexo, como Bohmerwald (2005), Paiva e Ramalho (2006), Baptista e Cunha (2007), Ferreira e Pithan (2008), Araújo e Curty (2008), Costa (2008) e Costa e Ramalho (2009; 2010).

Denominamos esse fazer dialógico entre os Estudos de usuários e os Estudos de usabilidade como "Estudos Híbridos de Uso da Informação" (COSTA; RAMALHO, 2010), enquanto área profícua de pesquisa na relação interdisciplinar entre, a priori, a Ciência da Informação e a Ciência da Computação, podendo-se ampliar esta relação no diálogo também com as Ciências do Comportamento, a Linguística, a Comunicação Social, a Ciência Cognitiva, a Lógica, a Administração, a Educação, a Sociologia, na perspectiva de melhor compreender o fenômeno do uso da informação por meio de sistemas interativos. Assim, os Estudos Híbridos de Uso da Informação se tornam necessários, emergindo diante das demandas da práxis social cotidiana no uso de sistemas interativos de informação na sociedade contemporânea.

Não adiantarão as idealizações de sistemas interativos de informação como repositórios virtuais, bases de dados eletrônicas, portais de informação, workflow, datamining, Enc. Bibli: Arquivol. Bibliotecon. Ci. Inf., ISSN 1518-2924, Florianópolis, v. 15, n. 30, p.57-73, 2010. 
datawarehouse, softwares direcionados aos usuários para recuperação de informação ou gerenciais voltados à tomada de decisão, sistemas interativos de telecomunicações, se não houver a satisfação daqueles que os utilizam. O que não dizer das bibliotecas digitais, dos arquivos digitais, dos repositórios digitais, dos museus virtuais, das modernas unidades de informação e de seus produtos tecnológicos a serviço dos usuários.

Sem querer definir tais produtos ou sistemas interativos de informação, por não ser o objetivo deste trabalho, valendo as suas indicações, consideramos que nenhuma arquitetura de informação, nenhuma modelagem computacional, nenhum design de quaisquer desses sistemas, portanto, terá verdadeira funcionalidade e razão de ser sem a escuta sensível dos seus usuários.

Aí está a função dos Estudos Híbridos de Uso da Informação, esforços interdisciplinares na investigação e promoção da melhor interação entre usuários e produtos ou sistemas de informação. Satisfazer os usuários, portanto, é essencial. E isto, porque, segundo Nielsen e Loranger (2007, p. 394), "no final, a única coisa que importa é se os usuários gostam do sistema e de utilizá-1o".

\section{MAIS ALGUMAS CONSIDERAÇÕES}

A pesquisa e avanço das TIC estão implicados no próprio desenvolvimento humano, a partir da atenção às (ilimitadas) necessidades humanas, acrescentando aí uma necessária discussão político-epistemológica da informação e da democratização de suas práticas sociais, da sua geração ao uso, conforme tratam autores como Castells (1999, 2000, 2001), Assman (2000), Lastres (1999), Lastres e Albagli (1999) e Sen (2000).

A satisfação das pessoas, diante da concretização de suas necessidades informacionais, pode inferir no sucesso/continuidade das organizações ou no seu contrário. Surge, assim, a exigência de realização de estudos de satisfação dos usuários da informação, reclamando Estudos de Usuários sob perspectivas renovadas, mais flexíveis/atualizadas diante da presente cultura da interface (JOHNSON, 2001), em virtude das TIC na sociedade contemporânea.

Dessa forma, dedicando-se a compreender o comportamento humano e a sua satisfação, tanto os Estudos de usuários quanto os Estudos de usabilidade podem incorrer/contribuir para a própria promoção do desenvolvimento humano. E nisso, implicamos a perspectiva conceitual 
que elaboramos à necessidade dos Estudos Híbridos de Uso da Informação, contemplando o fenômeno da satisfação de usuários da informação.

Dessa maneira, concluindo este trabalho, consideramos que a satisfação no uso dos sistemas e das suas informações pode desencadear a compreensão, a construção de conhecimentos, a emancipação, a autonomia, a escolha, a liberdade, ou não. Uma coisa é certa: a satisfação promove o retorno vital ao novo ponto de mutação, ou seja, novamente a insatisfação. Pois o que nos dói é que quando está tudo acabado, não há nada acabado, lembrar-nos-ia Millôr Fernandes, conforme escreveu no seu Poeminha de Insatisfação Absoluta:

\author{
O que me dói \\ É que quando está tudo acabado \\ Pronto pronto \\ Não há nada acabado \\ Nem pronto pronto...
}

\title{
NEW PERSPECTIVES OF USERS' SATISFACTION STUDIES
}

\begin{abstract}
This paper is product of debates and research concerning the satisfaction of information users, originated of the Group of Studies and Research in Reading, Organization, Representation, Production and Information Use entailed to the of Post-Graduation Program in Information Science from the Federal University of the Paraiba, having as laboratory the discipline Information Users of this program. It argues the definition of satisfaction related to the human necessities, privileging the informational optics in face of its importance in the present time, the Information Age. It presents the evolution of the satisfaction studies related to the information use through modern interactive systems in the perspectives of the Users' Studies of the Information Science and the Usability Studies of the Computer Science, considering the Hybrid Studies of Information Use.
\end{abstract}

Keywords: Satisfaction. Information use. Information users. Users'Studies. Usability.

\section{REFERÊNCIAS}

ANDERSON, Eugene; MITTAL, Vikas. The Satisfaction-Profit Chain. How Solid are the Links? Pittisburgh: University of Pittsburgh, 1999.

ASSMAN, Hugo. A metamorfose do aprender na sociedade da informação. Ciência da Informação. v. 29, n. 2, Brasília: IBICT, p. 7-15, maio/ago. 2000. 
ARAÚJO, Eliany Alvarenga de. A construção social da informação: práticas informacionais no contexto de Organizações Não-Governamentais/ONGs brasileiras. Brasília: UnB, 1998. 221 f. Tese (Doutorado em Ciência da Informação). Universidade de Brasília. 1998.

ARAUJO, Nelma Camelo de; CURTY, Renata Gonçalves. Análise da usabilidade de interfaces de repositório institucional: enfoque em uma ferramenta baseada em princípios ergonômicos. In: ENCONTRO NACIONAL DE PESQUISA E PÓS-GRADUAÇÃO EM CIÊNCIA DA INFORMAÇÃO, 9., São Paulo, Anais... São Paulo: ENANCIB, 2008.

BAPTISTA, Sofia Galvão; CUNHA, Murilo Bastos da. Estudo de usuários: visão global dos métodos de coleta de dados. Perspectiva em Ciência da Informação, Belo Horizonte, v. 12, n. 2, mai./ago. 2007.

BARANAUSKAS, Maria Cecília Calani; ROCHA, Heloisa Vieira da. Design e avaliação de interface homem-computador. São Paulo: UME-USP, 2000.

BARRETO, Aldo de Albuquerque. A questão da informação. Disponível em: <www.alternex.com.br/ aldoibict/quest/quest.htm>. Acesso em: 14 jan. 2002.

BEBER, Sidnei; RIBEIRO, José Luis; FOGLIATTO, Flávio. Satisfação e insatisfação: dois conceitos diferentes ou extremos de um mesmo continuum? In: ENCONTRO NACIONAL DE ENGENHARIA DE PRODUÇÃO, 24., 2004, Florianópolis. Anais... Florianópolis: ENEP, 2004.

BERNAL, John. Desmond. Preliminary analysis of pilot questionnaire on the use of scientific literature. In: The Royal Society Scientific Information Conference, 21 jun./2 jul. 1948, London, Proceedings: reports and papers submitted. London: The Royal Society, 1948.

BOHMERWALD, Paula. Uma proposta metodológica para avaliação de bibliotecas digitais: usabilidade e comportamento de busca por informação na Biblioteca Digital da PUC - Minas. Ciência da Informação, Brasília, DF, v. 34, n.1, p.95-103, jan./abr. 2005.

CASTELLS, Manuel. A era da informação: economia, sociedade e cultura; v. 1. A sociedade em rede. São Paulo: Paz e Terra, 1999.

A era da informação: economia, sociedade e cultura; v. 2. O poder da identidade. $3^{\mathrm{a}}$ ed. São Paulo: Paz e Terra, 2001.

. A era da informação: economia, sociedade e cultura; v. 3. Fim de milênio. $2^{\mathrm{a}}$ ed. São Paulo: Paz e Terra, 2000.

CHOO, Chun Wei. A organização do conhecimento: como as organizações usam a informação para criar significado, construir conhecimento e tomar decisões. São Paulo: Editora Senac, 2003, cap. 2, p. $63-126$.

COSTA, Luciana Ferreira da. Usabilidade do Portal de Periódicos da CAPES. João Pessoa: UFPB, 2008. 236f. Dissertação (Mestrado em Ciência da Informação). Universidade Federal da Paraíba. Disponível

em: $<$ http://dci2.ccsa.ufpb.br:8080/jspui/bitstream/123456789/99/3/Disserta\%c3\%a7\%c3\%a3o\%20Lucian a\%20Costa.pdf $>$. 2008.

; RAMALHO, Francisca Arruda. A usabilidade nos estudos de uso da informação: em cena, usuários e sistemas interativos de informação. Perspectivas em Ciência da Informação, v. 15, n. 1, p. 92-117, jan./abr. 2010. 
. O poder de Mnemósine: a memorização no uso da informação. In: CONGRESSO BRASILEIRO DE BIBLIOTECONOMIA, DOCUMENTAÇÃO E CIÊNCIA DA INFORMAÇÃO, 23., 5 a 8 jul. 2009, Bonito, Anais... Bonito: CBBD, 2009.

COSTA, Luciana Ferreira da; SILVA, Alan Curcino Pedreira da; RAMALHO, Francisca Arruda. (Re)visitando os estudos de usuários: entre a "tradição" e o "altenativo". Datagramazero - Revista de Ciência da Informação, v. 10, n. 4, p. 1-12, ago. 2009.

CYBIS, Walter. Ergonomia e usabilidade: conhecimentos, métodos e aplicações. São Paulo: Novatec Editora, 2007.

ESPERIDIÃO, Monique Azevedo; TRAD, Leny Alves Bomfim. Avaliação de satisfação de usuários: considerações teórico-conceituais. Cad. Saúde Pública, Rio de Janeiro, RJ, v. 22, n. 6, p. 1267-1276, jun. 2006.

FERREIRA, Aurélio Buarque de Holanda. Novo Dicionário Aurélio Eletrônico da Língua Portuguesa versão 5.0. 3. Ed., São Paulo: Editora Positivo, 2004.

FERREIRA, Sueli Mara Pinto. Novos paradigmas de informação e novas percepções de usuários. Ciência da Informação, Brasília, DF, v. 25, n.2, p. 217-223, maio/ago. 1996.

Estudo de necessidades de informação: dos paradigmas tradicionais à abordagem SenseMaking. 1997. Disponível em: <http://www.eca.usp.br/nucleos/sense/index.htm>. . Acesso em: 14 jan. 2002.

. PITHAN, Denise Nunes. Estudos de usuários e de usabilidade na Biblioteca INFOHAB: relato de uma experiência. Disponível $<$ http://eprints.org.archive/00011621/01Microsoft_Word_SIDI.2005_FerreiraPithan_15.outubro.pdf $>$ . Acesso em: 20. jan. 2008.

FIGUEIREDO, Nice Menezes de. Avaliações de coleções e estudos de usuários. Brasília: Associação dos Bibliotecários do Distrito Federal, 1979.

. Paradigmas modernos da Ciência da Informação. São Paulo: Polis, 1999.

GUINCHAT, Claire; MENOU, Michel. Usuários. In: Introdução geral às técnicas da informação e da documentação. Brasília: IBICT, 1994, p. 481-491.

ISO 9241. Ergonomic requirements for office work with visual display terminals. 1998.

JOHNSON, Steven. Cultura da interface: como o computador transforma nossa maneira de criar e comunicar. Trad. Maria Luisa Borges. Rio de Janeiro: Jorge Zahar, 2001.

LASTRES, Helena M. M. Informação e conhecimento na nova ordem mundial. Ciência da Informação, Brasília, v. 28, n. 1, p. 72-78, jan./abr. 1999.

; ALBAGLI, Sarita (Orgs.). Informação e globalização na era do conhecimento. Rio de Janeiro: Campus, 1999.

LE COADIC, Yves. A Ciência da Informação. Brasília: Briquet de Lemos, 1996.

MARTELETO, Regina Maria. Cultura, educação e campo social: discursos e práticas de informação. Rio de Janeiro: UFRJ, 1992. Tese (Doutorado em Comunicação). Escola de Comunicação/Universidade Federal do Rio de Janeiro, 1992. 
MARTIN-LAHERA, Yohannis. ¿Teoría o metateoría? En el dominio usuário. Ciência da Informação, Brasília, v. 33, n. 3, p.50-60, set./dez. 2004.

MASLOW, Abraham. Motivation and personality. New York: Harper \& Brothers, 1954.

MIRANDA, Silvânia. Como as necessidades de informação podem se relacionar com as competências informacionais. Ciência da Informação, Brasília, v. 35, n. 3, set./dez. 2006.

NIELSEN, Jakob. Changes in web usability since 1994. Dec. 1997. Disponível em $<$ http://www.useit.com/alertbox/9712 ${ }^{\mathrm{a}}$.html $>$. Acesso em: 18 nov. 2007.

Designing web usability. Indianápolis. New Riders, 1999.

. Projetando web sites. Rio de Janeiro: Campus, 2000.

Usability Engineering. San Diego: Academic Press, 1993.

NIELSEN, Jakob; LORANGER, Hoa. Usabilidade na web: projetando websites com qualidade. Rio de Janeiro: Editora Campus, 2007.

OLIVER, Richard L. Satisfaction: a Behavioral Perspective on the Consumer. Boston: Irwin McGraw-Hill, 1996.

PAIVA, Eliane; RAMALHO, Francisca Arruda. Usabilidade de softwares: um estudo com bibliotecas universitárias do nordeste brasileiro. In: SEMINÁRIO NACIONAL DE BIBLIOTECAS UNIVERSITÁRIAS, 2006. Salvador. Anais... Salvador: UFBA, 2006.

SANZ CASADO, Elias. Manual de estudios de usuarios. Madrid: Pirâmide, 1994.

SARACEVIC, Tefko. Ciência da Informação: origens, evolução e relação. Perspectivas em Ciência da Informação, v. 1, n. 1, p. 41-62, jan./abr., 1996.

SEN, Amartya K. Desenvolvimento como liberdade. São Paulo: Companhia das Letras, 2000.

SHNEIDERMAN, Ben. Design for computer systems. Addison-Wesley, 1987.

; PLAISANT, Catherine. Design the user interface: strategies for effective human-computer interaction. 4 ed. Addison-Wesley, 2004.

URQUHART, Donald J. The organization of the distribution of scientific and technical information. In: The Royal Society Scientific Information Conference, 21 jun./2 jul. 1948, London, Proceedings: reports and papers submitted. London: The Royal Society, 1948.

WILSON, Thomas D. On user studies and information needs. Journal of Documentation, London, v.37, n.1, p.3-15, Mar. 1981.

WURMAN, Richard Saul. Ansiedade de informação: como transformar informação em compreensão. São Paulo: Cultura, 1991.

Originais recebidos em: 08/12/2009

Aceito para publicação em: 21/06/2010 